\title{
Preparation and Properties of Hemp Stem Powder Reinforced Flexible Polyurethane Foams
}

\author{
Chao YING ${ }^{1}$, Li LIU ${ }^{1, a, *}$, Xin-Min HAO ${ }^{2}$, Jie HUANG ${ }^{3}$ \\ ${ }^{1}$ School of Materials Science and Engineering, Shanghai University, No.99 Shangda Road, \\ Baoshan District, Shanghai, China \\ ${ }^{2}$ The Quartermaster Research Institute of the General Logistics Department of the PLA, Beijing, \\ 100082, China \\ ${ }^{3}$ Li Ning (China) Sports Goods Co., Ltd \\ aliuli@staff.shu.edu.cn \\ ${ }^{*}$ Corresponding author
}

Keywords: Flexible Polyurethane Foam, Hemp Stem Powders, Morphology, Mechanical Property.

\begin{abstract}
In this article, a novel hemp stem powders (HSP) reinforced flexible polyurethane foam from polyols and diphenylmethane diisocyanate (MDI) has been prepared by self-rising method using water as blowing agent. The cell morphology of the HP reinforced foam was examined by scanning electron microscope (SEM). Besides, the influence of HSP content on the mechanical property such as tensile strength, compressive strength, and resilience were studied.
\end{abstract}

\section{Introduction}

With increasing interest in using renewable resources in the polyurethane foams and environmental protection consciousness, natural fibres as a relatively new group of environmental friendly materials are in considerable demand in recent years ${ }^{[1-4]}$. Banik et al ${ }^{[5]}$ studied the effect of cellulosic fiber from commercially available writing paper, bleached kraft pulp and rice flour on the properties of PUF. The compressive strength of modified samples was higher than that of the reference sample. Yuan et al. ${ }^{[6]}$ studied the influence of addition of wood flours on the properties of rigid polyurethane foams. The introduction of wood flour improved the compressive properties of porous composites, whereas flexural and tensile properties were decreased. The thermal stability of composites modified by wood flour was improved with the addition of natural fillers. Bledzki et al. ${ }^{[7]}$ studied the influence of woven flax and jute fabrics on PUR micro foams. They found that the increasing of the fibre content caused an improvement of the impact strength and shear modulus of investigated composites. The polyurethanes reinforced with woven flax fabric showed better mechanical strength than composites with woven jute fabrics. The other patents and articles have been issued in regard to the bio-PUF composite products ${ }^{[8-10]}$.

Hemp stem powders are low cost materials which are processed from hemp residues. It is a lignocellulosic material containing natural polymers, such as cellulose, hemicellulose, lignin, and tannins. HSP have been used in polypropylene, polyurethane coating, EVA foams etc ${ }^{[11-13]}$. However, HSP reinforced polyurethane foams seldom reported.

In this article, a novel flexible polyurethane foams extended with HSP using water as a blowing agent were prepared, and characterized their physical and mechanical properties, and to investigate the effects of HSP concentration on the PUF properties.

\section{Experimental}

\section{Materials}

The pMDI (PM200) was supplied by Wanhua Chemical Group Co., Ltd., China. The polyether polyol 330N (hydroxyl value $34 \pm 1 \mathrm{mgKOH} / \mathrm{g}$ ) was obtained from Changzhou Mid-Asia Chemical Co., Ltd., China. The polymer polyol 36/28 (hydroxyl value $30 \pm 5 \mathrm{mgKOH} / \mathrm{g}$ ) was provided by 
Maijia Co., Ltd., China. Distilled water generated in our laboratory was used as chemical blowing agent. Triethylene-diamine (TEDA), procured from Momentive Performance Materials, USA, and Bis (2-Dimethylaminoethyl) Ether (BDMAEE), supplied by Air Products and Chemicals, Inc., USA, were used as catalyst. Surfactant B8716 was obtained from Evonik Degussa. Hemp stem powders (particle size distribution $10 \sim 100 \mu \mathrm{m}$ ) were supplied by the Military Supplies Research Institute of the General Logistics Department of PLA.

\section{PU/HSP Foam Preparation}

The PUF samples were prepared by one-pot and free-rising method. Hemp stem powders were pre-dried to a constant weight in the oven at $105^{\circ} \mathrm{C}$. The polyol, catalysts, surfactant, and blowing agent (A-side material) were added by weighing into a disposable plastic cup and mixed at 3000 $\mathrm{rpm}$ for $1 \mathrm{~min}$ with a mechanical stirrer, at $25 \pm 2{ }^{\circ} \mathrm{C}, 45 \%$ relative humidity. Hemp stem powders was then added into A-side material and mixed at $3000 \mathrm{rpm}$ for 3 mins. The pMDI (B-side material) was then added rapidly. Stirring was continued for another $10 \mathrm{~s}$ at the same rpm. The mixtures were poured immediately into a mold and the foam was allowed to rise and set at $25 \pm 2^{\circ} \mathrm{C}$. The hemp stem powders concentration varied from 0 to $20 \%$. The PU/HP foam obtained were designated as HSP0 (matrix foam), HSP2.5, HSP5, HSP7.5, HSP10, HSP12.5, HSP15, HSP17.5and HSP20, according to their respective HSP content.

\section{PU/HSP Foam Property Characterization}

\section{Morphology}

The morphology of the PUF samples was examined with a scanning electron microscope (SEM) (phenom LT3687). The samples were gold coated before scanning. The accelerating voltage was 5 $\mathrm{kV}$. The SEM images were taken in different areas for each sample.

\section{Density Test}

The density of the PUF was determined by averaging the mass/volume measurement results of five specimens per sample following the procedure described in ASTM D3574 (section 9-15).

\section{Mechanical Property Test}

Hardness. Hardness was determined according to GB/T 10807-2006/ISO 2439:1997 by the Instron Universal Testing Machine, Model 1132 (Instron Corporation, Canton, MA) with a data acquisition system.

The Resilience Test. The resilience test is also referred to as the "ball rebound test." The instruments and the methods used conform to the ASTM D3574 (section 68-75).

Compression Test. The compressive properties of the foams were measured using an Instron universal testing machine (model 5500) in accordance with the GB/T 6669-2008/ISO 1856:2000 standard.

Tensile Strength Test. Tensile strength testing was performed in accordance with the procedure described in GB/T 6344-2008/ISO 1798: 2008.

\section{Results and Discussion}

\section{Density}

The densities of the PU/HP foam are presented in Fig.1. When the HSP increases from 0 to 20php, the densities of the PUF samples increase from 34 to $50 \mathrm{~kg} / \mathrm{m}^{3}$, respectively. 


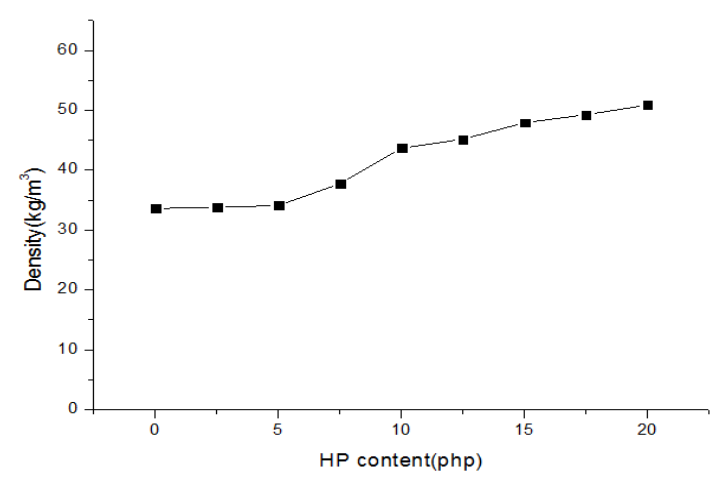

Fig.1 Effect of Hemp Stem Powders Content on Density of PU/HSP Foam

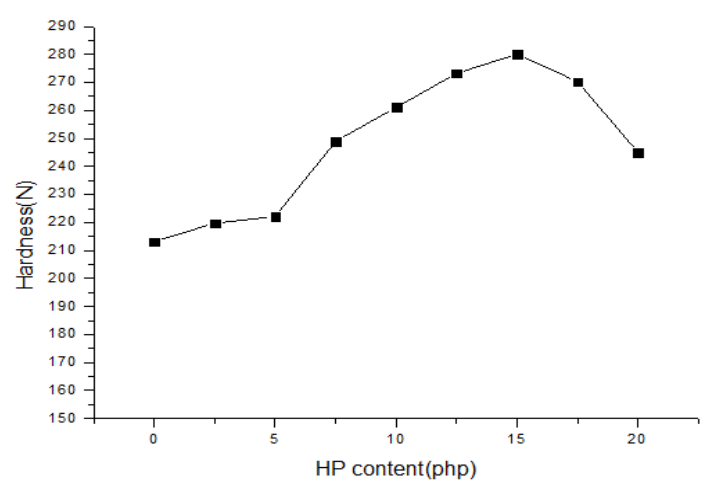

Fig.2 Effect of Hemp Stem Powders Content on Hardness of PU/HSP Foam

\section{Hardness}

Fig. 2 shows that the hardness of the PU/HSP foams samples are increased to $280 \mathrm{~N}$ with an increase in hemp stem powders from 0 to $15 \mathrm{php}$ and sharp decrease with higher content.

\section{Compression Set and Rebound Resilience}

Fig. 3 and Fig.4 shows the compression set and rebound resilience of the PU/HSP foam samples with the HSP content. When the HSP content increased from 0 to 20php, the compression set of the PUF samples increased, resilience decreased. This worse elastic recovery could be due to the energy dissipation contributed by the chain slipping along the particle surface ${ }^{[14-15]}$.

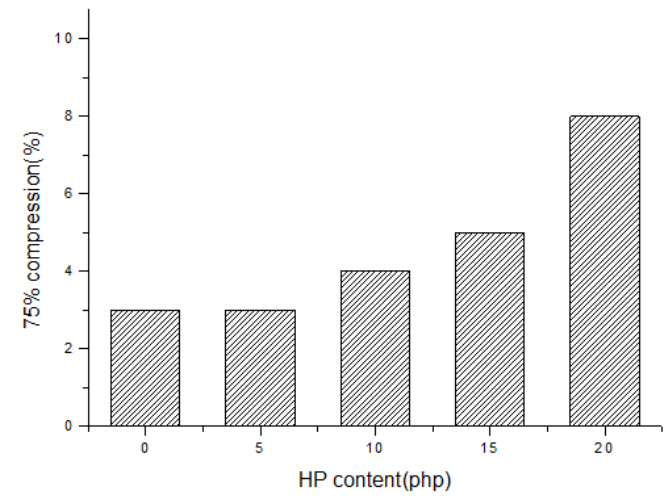

Fig. 3 Effect of HSP Content on Compressive Deformation of PU/HSP Foam

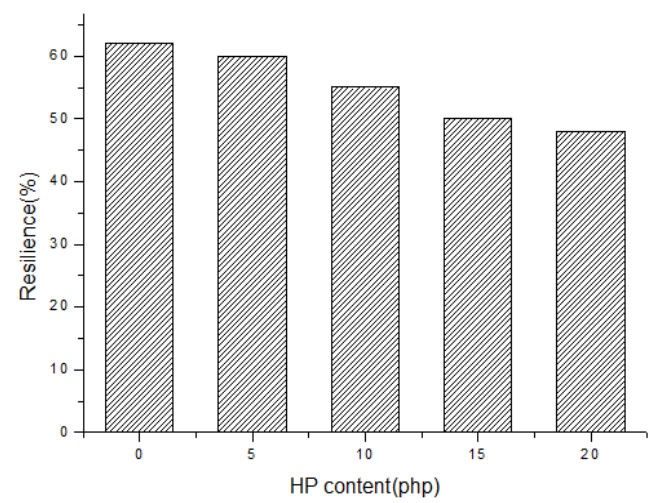

Fig.4 Effect of HSP Content on Resilience of PU/HSP Foam

\section{Tensile Strength and Elongation at Break}

Fig.5 shows the tensile strength of the PU/HSP foam samples with the HSP content. When the HSP content increased from 0 to $15 \mathrm{php}$, the tensile strength of the PUF samples increased from 108 to $140 \mathrm{KPa}$, respectively. The results may attribute to the HSP dispersed homogeneous in the PU matrix. However when the HSP increased from 15 to 20php, the agglomeration of HSP leaded to fracture of cell membrance, therefore, the tensile strength of the PUF samples decreased from 140 to $112 \mathrm{KPa}$, respectively.

Seen from Fig.5, elongation at break decreased with increase of HSP content. This tendency was related to the stress concentration from the agglomeration of HSP on the cell membrance. 


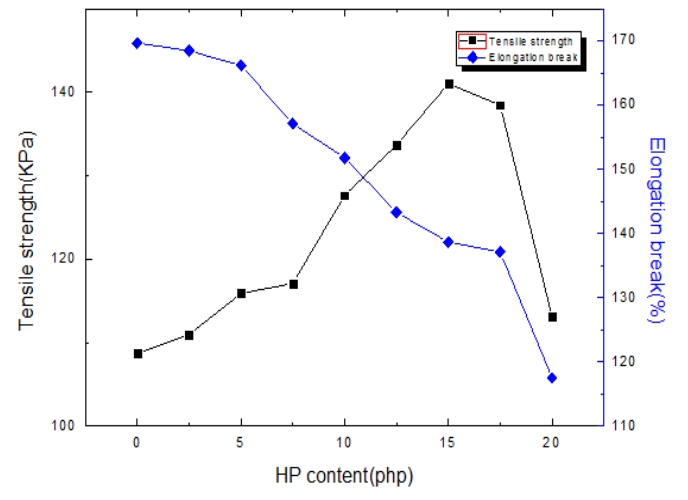

Fig.5 Effect of HP Content on Tensile Strength Areas of and Elongation at Break of PU/HSP Foam

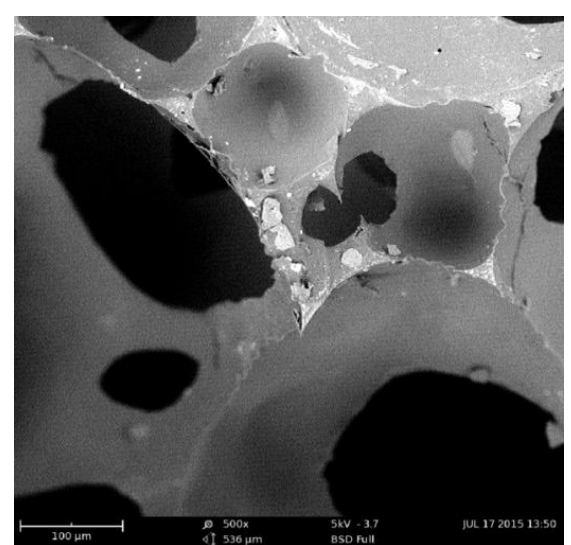

Fig.6 SEM Micrographs of Different Fracture of Prism for the Composite Foam

\section{Morphology}

Fig.6 shows the distribution of HSP in the structure of the PU/HSP foam from sample HSP20. Observed from Fig.6, exist of HSP in the cell prism leads to more interstices which would decrease the strength of cell prism. This structure explains the decrease of mechanical property at macro level.

With the increase of the hemp stem powders concentration up to $20 \mathrm{php}$, the resin mixture become too viscous to disperse homogeneous, Which leads to a corresponding reduction of heterogeneous nucleation site. The poorly dispersed hemp stem powders tend to agglomerate, and the agglomeration could not be well wetted. A high pressure area is formed on contact surface that have contact angel more than 90 degree, seen from Fig.7, which would drive the liquid flow to boundarys of plateau, thus accelerating the reduction of cell wall thickness ${ }^{[16]}$. Once the cell wall is reduced to a certain level, the cell will rupture. When hemp stem powders concentration exceed $15 \mathrm{php}$, the cell size become bigger and the cell size distribution become broader because of cell coalescence.

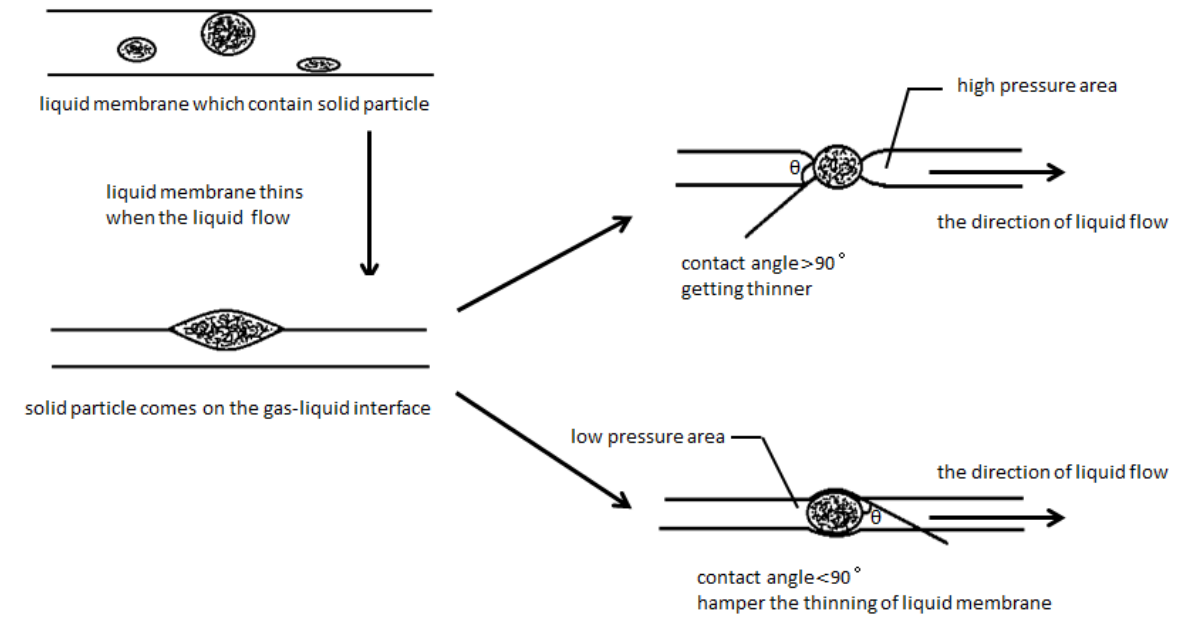

Fig.7 The Influence of Hemp Stem Powders on Foaming

\section{Conclusions}

A HSP reinforced flexible polyurethane foams were prepared using water as blowing agent. The addition of HSP below the amount of $15 \mathrm{php}$ had beneficial influence on physical and mechanical properties. An incorporation of $15 \mathrm{php}$ HSP in PUF improved the density by about $41 \%$ to $50 \mathrm{~kg} / \mathrm{m}^{3}$, the hardness by about $31 \%$ to $280 \mathrm{~N}$ and tensile strength by about $30 \%$ to $300 \mathrm{~N} / \mathrm{m}$. On the other 
hand, the incorporation of HSP resulted in a small reduction of elongation at break and resilience. These PU/HSP foams showed an improvement of antibacterial property. Because of the good physical mechanical and antibacterial properties, these PU/HSP foams would be applied in shoe material, cushion packaging material and house furnishing material.

\section{Acknowledgement}

This work was supported by the National High-tech R\&D Program (863 Program) (SQ2015AA033905).

\section{References}

[1] Bledzki A K, Jaszkiewicz A. Mechanical performance of biocomposites based on PLA and PHBV reinforced with natural fibres-A comparative study to $\mathrm{PP}[\mathrm{J}]$. Composites science and technology, 2010, 70(12): 1687-1696.

[2] Dhakal H N, Zhang Z Y, Richardson M O W. Effect of water absorption on the mechanical properties of hemp fibre reinforced unsaturated polyester composites[J]. Composites Science and Technology, 2007, 67(7): 1674-1683.

[3] Krishnamurthi B, Bharadwaj-Somaskandan S, Sergeeva T, et al. Effect of wood flour fillers on density and mechanical properties of polyurethane foams[J]. Cellular polymers, 2003, 22(6): 371-381.

[4] Brahmakumar M, Pavithran C, Pillai R M. Coconut fibre reinforced polyethylene composites: effect of natural waxy surface layer of the fibre on fibre/matrix interfacial bonding and strength of composites[J]. Composites Science and Technology, 2005, 65(3): 563-569.

[5] Banik I, Sain M M. Water-blown soy polyol based polyurethane foams modified by cellulosic materials obtained from different sources[J]. Journal of applied polymer science, 2009, 112(4): 1974-1987.

[6] Yuan J, Shi S Q. Effect of the addition of wood flours on the properties of rigid polyurethane foam[J]. Journal of applied polymer science, 2009, 113(5): 2902-2909.

[7] Bledzki A K, Zhang W, Chate A. Natural-fibre-reinforced polyurethane microfoams[J]. Composites Science and Technology, 2001, 61(16): 2405-2411.

[8] Rozman H D , Tay G S , Abusamah A .The effect o f glycol gype, glycol mixture , and isocyanate/glycol ratio on flexural properties of oil palm empty fruit bunch-polyurethane composites .J Wood Chem Techn, 2003 , 23(3 \& 4):249.

[9] Kuranska M, Aleksander P, Mikelis K, et al. Porous olyurethane composites based on bio-components[J]. Compos Sci Techn, 2013, 75(0): 70.

[10] Rácz I, Andersen E, Aranguren M I, et al. Wood Flour-Recycled Polyol Based Polyurethane Lightweight Composites[J]. Journal of composite materials, 2009, 43(24): 2871-2884.

[11] Han H C, Gong X L. One-step green treatment of hemp fiber used in polypropylene composites[J]. Polymer Composites, 2014.

[12] Hao X M, Yang Y. Property and Application of PU Coating Modified with Hemp Stem Superfine Powder. Textile Bioengineering and Informatics Symposium Proceedings[c]. Beijing, 2011.

[13] Hao X M, Ma W J, Gan G, et al. Analysis of Novel Structure of EVA/Hemp Stem Powder Foam Materials[C]//Advanced Materials Research. Trans Tech Publications, 2012, 627: 651-654.

[14] Wu Y P, Ma Y, Wang Y Q, et al. Effects of characteristics of rubber, mixing and vulcanization on the structure and properties of rubber/clay nanocomposites by melt blending[J]. Macromolecular 
Materials and Engineering, 2004, 289(10): 890-894.

[15] Gatos K G, Sawanis N S, Apostolov A A, et al. Nanocomposite Formation in Hydrogenated Nitrile Rubber (HNBR)/Organo-Montmorillonite as a Function of the Intercalant Type[J]. Macromolecular materials and engineering, 2004, 289(12): 1079-1086.

[16] Frye G C, Berg J C. Mechanisms for the synergistic antifoam action by hydrophobic solid particles in insoluble liquids[J]. Journal of colloid and interface science, 1989, 130(1): 54-59. 